\title{
MANUEL LÓPEZ CEPERO (1778-1858) Y LA PINTURA SEVILLANA DE SU TIEMPO
}

\section{MANUEL LÓPEZ CEPERO (1778-1858) AND THE SEVILLE PAINTING OF HIS TIME}

\author{
Pedro J. Martínez Plaza \\ Museo Nacional del Prado, Madrid. España \\ pedroj.martinez@museodelprado.es
}

\begin{abstract}
El artículo estudia la relación de Manuel López Cepero (1778-1858) con algunos de los principales artistas sevillanos de su tiempo, a los que implicó en diferentes encargos, en su mayoría totalmente desconocidos. Entre ellos destaca, por su envergadura, la nueva decoración para el coro de la catedral de Sevilla, que no llegó a materializarse. El análisis de algunos documentos inéditos de su archivo personal permite conocer también otros proyectos, como la creación de una particular iconoteca, y ponderar su papel en la promoción de los jóvenes pintores de la ciudad, de los cuales se identifican diferentes obras inéditas que pertenecieron a este coleccionista.

Palabras clave: Antonio María Esquivel; Antonio Cabral Bejarano; José Gutiérrez de la Vega; John Hoppner; catedral de Sevilla.
\end{abstract}

This paper focuses on the activities of Manuel López Cepero (1778-1858), dean of Seville Cathedral, as a patron of art, based on the analysis of his private archive. It reveals several hither to unknown commissions made by Cepero to some of the most important painters of Seville at the time. The ambitious new decoration for the choir of the cathedral stands out among these projects, although it was in fact never realized. The scrutiny of Cepero's personal documents also provides new information on other projects, such as his peculiar portrait gallery, and his role in the promotion of young artists in Seville, of which he collected several works, that remain unpublished until today.

Keywords: Antonio María Esquivel; Antonio Cabral Bejarano; José Gutiérrez de la Vega; John Hoppner; Seville Cathedral.

\section{EL DEÁN MANUEL LÓPEZ CEPERO}

Manuel López Cepero (Jerez de la Frontera, Cádiz, 1778-Sevilla, 1858) fue un destacado personaje de la primera mitad del siglo XIX, especialmente en Sevilla, donde llegó a ser deán de la catedral, pero también en Madrid, pues ocupó 
numerosos cargos como diputado, senador vitalicio y académico de la Academia de Bellas Artes de San Fernando y de la Real Academia Española (Figura 1). Diferentes estudios han analizado su relevancia en la historia política y cultural de su época ${ }^{1}$, así como su participación en el comercio de obras de arte y la excelencia de su colección ${ }^{2}$. Esta, que a la muerte del deán contaba con más de mil pinturas, puede ser considerada, con toda seguridad, como una de las más numerosas de toda la centuria en España. La importancia de la misma se debe en buena medida a la pintura barroca que poseía, sobre todo de la escuela sevillana, como la Inmaculada de Velázquez (Fundación Focus Abengoa) y el San Miguel de Murillo (Viena, Kunsthistorisches Museum), y así fue ponderada por la mayoría de sus contemporáneos ${ }^{3}$. Entre estos, tan solo Amador de los Ríos, en dos de sus obras dedicadas a la ciudad de Sevilla, hizo alusión a la presencia en ella de pintura contemporánea ${ }^{4}$. El espacio que le dedica a esta parte en Noticia de los principales monumentos artísticos de Sevilla (1842) revela, sin duda, la importancia que la

* Este artículo no podría haberse realizado sin la generosa colaboración de los descendientes de López-Cepero, a los que deseo expresar aquí mi agradecimiento: Teresa, Ignacio y José María López-Cepero, José Luis Fábrega, Carmelo Javier Merchán y Pablo Fossas, así como también a fray Guillermo Cerrato y a Evaristo Pineda. Merecen también mi gratitud Javier Barón, Pablo Melendo, John Wilson, Silvia Castillo y el personal del Archivo de la Catedral de Sevilla.

${ }^{1}$ Véase fundamentalmente TERUEL GREGORIO DE TEJADA, Manuel: "Rasgos claves de la vida de Manuel López Cepero", Archivo hispalense, 124, 1964, pp. 157-191; TERUEL GREGORIO DE TEJADA, Manuel: "Ideología política del diputado de Cádiz Manuel López Cepero”, Archivo hispalense, 139-140, 1966, pp. 217-245; RUIZ LAGOS, Manuel: El Deán López Cepero y la Ilustración Romántica. Jerez de la Frontera, 1970; RUIZ LAGOS, Manuel: Epistolario del Deán López Cepero. Anotaciones a un liberal romántico. Jerez, 1778-Sevilla, 1858. Jerez de la Frontera, 1972; y RUIZ LAGOS, Manuel: Ilustrados y reformadores en la Baja Andalucía. Madrid, 1974, pp. 90-126.

2 Para lo primero véase MARTÍNEZ PLAZA, Pedro J.: "Un encargo "cuadresco" para el marqués de Salamanca, correspondencia entre José María Huet y Manuel López Cepero en 1848", Cartas Hispánicas, 4, 18-11-2015; y MARTÍNEZ PLAZA, Pedro J.: "Manuel López Cepero (1778-1858) and the trade in paintings between Madrid and Seville in the first half of the nineteenth century", Journal of the History of Collections, 28, 2016, pp. 73-84. Para el conocimiento de su colección sigue siendo fundamental MERCHÁN CANTISÁN, Regla: El deán López-Cepero y su colección pictórica, Sevilla, 1979. Véase también MERCHÁN CANTISÁN, Regla: Catálogo de la colección pictórica del deán López Cepero. Memoria de Licenciatura inédita, Universidad de Sevilla, 1979.

3 Véase especialmente FORD, Richard: A Handbook for travellers in Spain. París, 1855, p. 188; BEGIN, E.: Voyage pittoresque en Espagne et en Portugal. París, 1852, p. 464; y AUDIN, J. M. V.: Guide du voyageur en Espagne et en Portugal. París, 1853, p. 683.

${ }^{4}$ AMADOR DE LOS RÍOS, José: Noticia de los principales monumentos artísticos de Sevilla. Sevilla 1842, pp. 57-58; y AMADOR DE LOS RÍOS, José: Sevilla pintoresca o descripción de sus más célebres monumentos artísticos. Sevilla, 1844, p. 456. 
misma debió tener para el deán, quien además mantuvo una relación cercana con el autor de esta obra, lo que da mayor valor a este testimonio.

El inventario que se realizó del total de esta colección a la muerte de Cepero, y que aún permanece inédito ${ }^{5}$, revela mejor que los catálogos de venta -de 1860 en Sevilla, con 889 lotes, y de 1868 en París, con 52 lotes- el estado de esta al fallecimiento de su propietario. El documento recoge la totalidad de las obras, muchas de las cuales -más de un centenar- no fueron incluidas en la venta de 1860; además, incluye anotaciones de gran valor, que no aparecen en los catálogos, donde sus sobrinos obviaron o eludieron determinada información, como que algunos de los cuadros eran copias de originales. En el inventario se contabilizan hasta sesenta pinturas de artistas contemporáneos, en su mayoría de la escuela andaluza. Destacan también hasta cinco de Francisco de Goya, de las cuales solo está identificada como de su mano el retrato de Francisca Vicenta Chollet (Pasadena, Norton Simon Foundation), mientras que las otras cuatro, catalogadas como "capricho", debían ser simples escenas goyescas, posiblemente imitaciones. Por otros documentos de su archivo personal, sabemos que Cepero también poseyó o comerció con obras de Mariano Salvador Maella, Zacarías González Velázquez y Bartolomé Montalvo, pero este último es el único de todos ellos del que conservaba pinturas a su muerte ${ }^{6}$.

Las sesenta obras realizadas por artistas en activo o fallecidos en el transcurso del siglo XIX evidencian un claro interés por la pintura contemporánea. Este puede ser estudiado, además, a través de numerosas cartas y anotaciones diversas procedentes de su archivo, así como mediante la identificación y localización de algunos de los cuadros que, a pesar de la dispersión que la colección ha tenido, aún conservan sus descendientes. Todo ello pone de manifiesto la relación tan cercana del deán con los pintores sevillanos más destacados de su época, como Antonio Cabral Bejarano, José Gutiérrez de la Vega y Antonio María Esquivel, así como su participación directa en la que hubiera podido llegar a ser una de las empresas artísticas más destacadas de la primera mitad de siglo XIX en Sevilla, y que hasta ahora resultaba prácticamente desconocida ${ }^{7}$, quizá porque no

5 Archivo de la Provincia Bética Franciscana, Espartinas (Sevilla), Archivo del Deán López-Cepero (A.D.L.-C.), leg. 5/660. Este inventario manuscrito es un borrador realizado durante las operaciones de división de sus bienes.

${ }^{6}$ Las obras de estos artistas aparecen en sus anotaciones y cuentas, siendo Goya el que lo hace con mayor frecuencia: A.D.L.-C., 1/160, 1/175, 1/190, 1/201, 1/231b.

${ }^{7}$ La primera y única alusión contemporánea a este proyecto fue realizada por AMADOR DE LOS RÍOS, J.: Noticia de los principales monumentos..., op. cit., pp. 57-58; y AMADOR DE LOS RÍOS, J.: Sevilla pintoresca..., op. cit., p. 456. Para la historia del coro de la catedral véase sobre todo HERNÁNDEZ GONZÁLEZ, Salvador: La escultura en madera del Gótico final en Sevilla. La sillería del coro de la Catedral de Sevilla. Sevi1la, 2014, especialmente p. 75. 
llegó a materializarse y porque sus contemporáneos y biógrafos, por eso mismo, obviaron cualquier alusión al respecto ${ }^{8}$. Se trata del proyecto de redecoración de la sillería de la catedral de Sevilla, en el cual Cepero puso especial empeño pues, casi con toda seguridad, se debió a su propia iniciativa.

\section{UN PROYECTO PARA EL CORO DE LA CATEDRAL DE SEVILLA}

El 14 de noviembre de 1835 Cepero había sido nombrado canónigo de la catedral de Sevilla y el 31 de octubre del año siguiente mayordomo de fábrica'. Como consecuencia de ello, decidió emprender una serie de reformas y empresas dedicadas a engrandecer y renovar la sede hispalense. En 1837 impulsó la creación de un panteón de sevillanos ilustres en el trascoro de la misma y el traslado hasta allí de algunos enterramientos de diferentes iglesias y conventos ${ }^{10}$, de lo cual se encargarían el canónigo Francisco Pereira y él mismo ${ }^{11}$. Para entonces, Cepero debía tener también proyectada la nueva decoración para el coro catedralicio, tal y como demuestra una carta que le envió desde Madrid el 7 de febrero de ese año Félix José Reinoso (1772-1841), escritor, jurista y sacerdote nacido en Sevilla, a quien Cepero conocía con el apelativo de Fileno ${ }^{12}$. En ella ${ }^{13}$, este le iba dando respuesta a las diferentes ideas que el deán le había comentado en una misiva del día 15 de enero, que no se conserva. Así, Fileno daba su aprobación a la distribución por el interior de la catedral de diferentes cuadros procedentes de los conventos sevillanos desamortizados, con los que el deán deseaba "un enriquecimiento artístico del templo" y hacía diversas observaciones a la traslación de los sepulcros. Respecto al coro, el rechazo de Reinoso resultó tajante y la extensión de su comentario permite conocer muchos de los detalles de este proyecto. Este consistía en la colocación de diferentes pinturas contemporáneas en los respaldos de la sillería alta del coro, que estaban decorados desde su construcción a finales del siglo XV y principios del siglo XVI con una sencilla decoración geométrica de lacería en taracea: "Lo que no me parece bien, es el pensamiento de los cuadritos en los respaldos de las sillas del coro. Con la escultura gótica del coro, con el color

${ }^{8}$ Incluso el propio Cepero, en una memoria autobiográfica ya publicada, no recogía ni una sola mención al mismo: PABÓN, Jesús: "Del Deán López Cepero, apunte autógrafo y autobiográfico", Boletín de la Real Academia de la Historia, CLXXI, 1974, pp. 453-477.

${ }^{9}$ MERCHÁN CANTISÁN, R.: El deán López-Cepero..., op. cit., pp. 26-27.

${ }^{10}$ ROS GONZÁLEZ, Francisco S.: "Manuel López Cepero y la reforma de la iglesia de la Universidad de Sevilla", Laboratorio de Arte, 19, 2006, pp. 433-434.

${ }^{11}$ Así lo estableció el cabildo en sesión de 18 de enero de 1837. Archivo de la Catedral de Sevilla (A.C.S.), Secretaría, lib. 200, sig. 7248, f. 11v.

${ }^{12}$ Sobre este personaje es fundamental RÍOS SANTOS, Antonio Rafael: Vida y poesía de Félix José Reinoso. Sevilla, 1989.

13 A.D.L.-C., sin sig., carta de Reinoso a Manuel López Cepero, Madrid, 7-2-1837. 
oscurísimo y vetusto de la madera; han de hermanar tan mal estas pinturas fresquitas, que cubrirán alguna parte de sus ornatos, aunque solo sean de embutidos; ¡que solo servirán para romper el tono austero y uniforme de la sillería!... ¿Y qué memoria quieres consignar a la posteridad? ¿No valdría más olvidarla? Yo no sé qué pintores restan en Sevilla, pero sé que serán muy malos. Probablemente Gutiérrez y Bejarano, son los que más conservan el estilo de la escuela sevillana, y no hablo de Esquivel, porque aunque con algún genio es farfullador; y esos están en Madrid, y esos no saben hacer más que copias o retratos. Pero ¡cuadros originales! Paréceme que se ha de mirar ese pensamiento como una emulación del riquísimo coro de Toledo, donde hay tantos santos, tantos ángeles, profetas y apóstoles, y muchos más de los que tú quieres, todo de admirable escultura; y ha de calificarse como una empresa imposible acometida con medios miserables. Esa colección, si se quiere conservar, pudiera ponerse en la biblioteca o en alguna oficina. El coro con esas pinturitas parecerá una vieja chafarrinada de colorines".

Parece claro que este proyecto debió ser impulsado por el propio deán, y no por el cabildo, como se pensaba ${ }^{14}$, lo que explicaría también que este asunto no fuera tratado en ninguna de las reuniones de esta corporación ${ }^{15}$. Las decoraciones originales de taracea hacían que el conjunto resultara demasiado sencillo y sobrio, sobre todo si se le comparaba con el de la catedral primada de Toledo, mucho más rico, y al cual Cepero pretendía emular. Por lo que sabemos, las obras serían, al menos, las siguientes: doce pinturas de los apóstoles, siete de los arcángeles -Miguel, Rafael, Gabriel, Uriel, Jehudiel, Barachiel y Seathiel-, una del ángel custodio y otras dos con grupos de ángeles, otra de San Juan Bautista y un número no determinado de diferentes santos vinculados a la iglesia sevillana, como las Santas Justa y Rufina y San Fernando y San Hermenegildo. Diecisiete de estas pinturas y diez de sus bocetos aparecen en el inventario post mortem del deán ${ }^{16}, \mathrm{y}$ un buen número de ellos continúan en manos de sus descendientes, entre los que hay algunos ya conocidos, mientras otros se dan a conocer en este artículo por vez primera. Las pinturas definitivas tienen las mismas medidas $(133 \mathrm{x}$ $53 \mathrm{~cm}$ ), a excepción de los dos grupos de coros angélicos, que son diez centímetros más altos. A estas 27 pinturas habría que sumar algunas más-desconocemos cuántas- que se iban a encargar a otros pintores residentes en Madrid. Con todos ellos parece que solo lograría cubrirse una parte muy pequeña del total de los estalos, probablemente los más cercanos a la silla presidencial, si bien ninguna de

${ }^{14}$ Así lo señaló GUERRERO LOVILLO, J.: Antonio María Esquivel. Madrid, 1957, p. 25.

15 A.C.S., Secretaría, serie de Actas capitulares, 1835 (lib. 198, sig. 7246), 1836 (lib. 199, sig. 7247) y 1837 (lib. 200, sig. 7248).

16 A.D.L.-C., 5/660. Los ángeles presentan los siguientes números: 40, 41, 644, 729, 730, 773, 774, 781 y 782; los bocetos: 626-634, 629 y 630 y el San Juan Bautista, el 645. 
las obras estudiadas presenta identificación alguna en el reverso que ayude a conocer su ubicación exacta en el coro.

Esta reforma resultaba de especial calado dentro de todas las emprendidas por Cepero en la catedral desde 1836, pues era la única que implicaba un encargo ex profeso para un lugar concreto y, además, suponía la implicación de diferentes artistas contemporáneos, en lo que, de haberse materializado, hubiera sido uno de los principales conjuntos pictóricos de la primera mitad del siglo XIX en un lugar de culto, no solo en la ciudad de Sevilla. La intención demuestra la influencia que tuvieron en el pensamiento del deán las ideas ilustradas, pues algunos teóricos del siglo XVIII se habían ocupado de teorizar y ofrecer soluciones sobre estos espacios catedralicios tan característicos de la arquitectura española. Así, mientras Antonio Ponz se había mostrado en contra de ellos en la carta dedicada a la catedral de Jaén, Jovellanos había defendido el emplazamiento original de los mismos en la nave central en su Disertación sobre el traslado del coro de la Catedral de Palma ${ }^{17}$. En cambio, Ceán Bermúdez, su discípulo, reflexionaba sobre la necesidad de corregir el "embarazoso" ejemplo del coro en medio de las catedrales en su Descripción artística de la catedral de Sevilla ${ }^{18}$. Cepero, que mantuvo una cercana amistad con este último durante los años en que escribió el libro, y que llegó a plantearse en 1840 la reedición del mismo ${ }^{19}$, no debió ser ajeno a este debate y apostó por mantener la integridad del coro, pero con una renovación de su interior.

Cepero había pensado en un primer momento en artistas sevillanos, los cuales, como indica Reinoso, "conservan el estilo de la escuela sevillana", lo que demuestra su intención de lograr un conjunto con un estilo unitario. Entre los elegidos estaba Antonio Cabral Bejarano (1798-1861), uno de los pintores más importantes en el panorama artístico sevillano de su tiempo y que, a diferencia de Gutiérrez de la Vega y de Esquivel, residía y trabajaba en Sevilla. Como autor de los siete arcángeles, el ángel custodio, el San Juan Bautista y los dos grupos de ángeles -de todos los cuales llegó a presentar el respectivo boceto a Cepero-, es el artista que más obras realizó, y también ha sido del que más obras se han localizado: cuatro bocetos de presentación y dos pinturas acabadas. Cabe pensar que, aunque el deán mantuvo cierta relación -sobre todo comercial-con su padre Joaquín ${ }^{20}$, debió escoger al hijo por las razones que esgrimía Reinoso en su

${ }^{17}$ NAVASCUÉS PALACIO, P.: Teoría del coro en las catedrales españolas. Madrid, 1998, pp. 116-117.

${ }^{18}$ CEÁN BERMÚDEZ, Juan Agustín: Descripción artística de la catedral de Sevilla. Sevilla, 1804, p. XXXVIII y p. 46.

19 Así se deduce de una carta enviada por Reinoso a Cepero el 28 de febrero de 1840, publicada en RUIZ LAGOS, M.: Epistolario del Deán López Cepero..., op. cit., carta $\mathrm{n}^{\circ} 72$.

${ }^{20}$ En el archivo del deán solo se conservan determinadas referencias a este artista, relativas sobre todo a la tasación y valoración de pinturas: dos cartas enviadas por Francisco 
carta. En efecto, la huella de Murillo es patente en algunos de los bocetos, como en el Arcángel Rafael (Figura 2), cuyo recuerdo al maestro sevillano es más que evidente tanto en la composición como en el modelo, de claro recuerdo murillesco. Al igual que los bocetos de Uriel (Figura 3) y Seathiel (Sevilla, colección particular), presenta un fondo dorado, distinto al San Juan Bautista (Sevilla, colección particular), que se abre a un paisaje. De las pinturas definitivas, se han identificado dos: Jehudiel y San Miguel arcángel (ambas en colección particular). El primero resulta más interesante que el segundo, cuya composición adolece de un estatismo excesivo, frente a la postura más dinámica del otro arcángel, que, como en los bocetos de Uriel y Seathiel, se arrodilla sobre una nube, repitiendo así la misma fórmula compositiva en estos tres casos. La orientación de Uriel hacia la derecha y de Seathiel hacia la izquierda permite pensar que el artista concibió la disposición de muchos de estos arcángeles afrontados por parejas.

Tanto los arcángeles como los apóstoles de Esquivel presentan un fondo neutro, de luces doradas, y todos están firmados y fechados, por sus respectivos autores, en 1837. Una serie de cartas enviadas por Antonio María Esquivel (1806-1857) a Cepero, inéditas hasta la fecha, permiten conocer más detalles de este proyecto y de la participación de este en el mismo. El pintor realizó siete apóstoles: San Mateo (Figura 4), Santiago el Menor, San Pablo (los tres en el Museo del Romanticismo), San Simón (Figura 5) y San Felipe, San Judas Tadeo (ambos en mercado del arte, 2017) y Santo Tomás (en paradero desconocido). Seis de ellos fueron expuestos en el Liceo Artístico y Literario de Madrid en $1837^{21}$. Es posible que poco después llegaran a Sevilla, donde no debieron ser del total agrado del comitente. Así, en una carta de Esquivel a Cepero el 22 de enero de 1838 , aquel lamentaba que no le hubieran gustado sus apóstoles ${ }^{22}$. El tono empleado en la disculpa no debió agradar al deán, como demuestra otra misiva de Esquivel, de 20 de febrero de $1838^{23}$. En ella el pintor se disculpaba de nuevo por "no haber llenado enteramente los deseos de V. en el desempeño de los apóstoles" y afirmaba que estos "no dejaban de ser de la escuela sevillana, aunque no fueran imitaciones de Murillo", confesando que a él le "era imposible hacer lo que hizo Murillo, no porque no quiera, si no porque no puedo por mi carácter o por mi poca disposición, y no pudiendo imitarlo, solo conseguiría hacer un recuerdo ridículo y exajerado [sic]". Esta confesión, de gran interés para profundizar en el

de Paula López de Castro a Cepero, 22 y 26 de junio de 1822. A.D.L.-C., leg. 1/92 y A.D.L.C., sin sig.

${ }^{21}$ PÉREZ SÁNCHEZ, Aránzazu: El Liceo artístico y literario de Madrid (18371851). Madrid, 2005, apéndice III.

${ }_{22}$ A.D.L.-C., leg. 1/106, carta de Antonio María Esquivel a Manuel López Cepero, Madrid, 22-1-1831.

23 A.D.L.-C., leg. 8/1, carta de Antonio María Esquivel a Manuel López Cepero, Madrid, 20-2-1838. 
pensamiento artístico de uno de los mejores pintores sevillanos de la centuria antepasada, muestra también hasta qué punto el deán se implicó en el resultado final del proyecto y concibió el conjunto, al menos en un primer momento, como una nueva manifestación del estilo murillesco, que el comitente consideraba el más representativo de la escuela sevillana.

Tras pedir disculpas por el malentendido, Esquivel señaló que "le he hablado a varios artistas y entre ellos Dn. Vicente López hará uno; otro Gutiérrez, otro Dn. José Elbo, otro haré yo, todos sin ningún interés". Aunque desconocemos a qué cuadros se refiere, debían ser sin duda también para el coro. Es significativo que Cepero pensara en diferentes artistas madrileños, de tendencias estéticas completamente dispares, y entre los que solo Gutiérrez de la Vega presentaba un estilo afín a sus gustos, mientras que Vicente López (1772-1850), por ejemplo, representaba un academicismo más conservador, que sin embargo no debía desagradar a Cepero, teniendo en cuenta que en su colección poseyó por ejemplo obras de Maella, maestro de aquel.

Esquivel aludía en la misma carta a la mediación de Juan Nicasio Gallego (1777-1853), poeta, político y académico, y uno de los amigos más cercanos de Cepero; y le indicaba que Gallego hablaría con Vicente López, amigo de este, "y algún otro, aunque tanto Dn. Nicasio como yo esperamos mal resultado, es decir, que no quieran hacer los cuadros sin interés ninguno", y añadió que "Federico Madrazo y Carlos Rivera están en París y no se puede contar con ellos". Todo parece indicar que la intención de Cepero era recabar la colaboración de aquellos artistas que, por juventud o por cercanía, podían prestarse a colaborar de manera gratuita y desinteresada en el proyecto. De ahí que acudiese a los jóvenes Federico de Madrazo (1815-1894) y Carlos Luis de Ribera (1815-1891), o a los sevillanos José Elbo Peñuelas (1804-1844) y José Gutiérrez de la Vega. De haberse logrado la participación de todos estos artistas, se habría conseguido un resultado poco homogéneo, con estilos muy diversos, incluso antagónicos, muy diferente a su primera intención. El conjunto, eso sí, se hubiera convertido en fiel reflejo de la riqueza del panorama artístico de la corte en estas décadas, donde convivieron los últimos rescoldos dieciochescos de López, los continuadores de la tradición pictórica del Siglo de Oro - con Esquivel y Gutiérrez de la Vega- y las nuevas modas internacionales de Federico de Madrazo y Carlos Luis de Ribera.

Aunque no parece que llegase a tener relación con Elbo, ya que no conservaba ningún cuadro a su muerte y su nombre no aparece en ningún documento de su archivo, con José Gutiérrez de la Vega (1791-1865) sí debía tener cierta amistad. Así lo demuestra el retrato que le realizó en 1817 (Figura 1). Quizá por ello decidió encargarle los otros seis apóstoles, que no han sido identificados, pues ni siquiera hay constancia de que fueran pintados. De hecho, la única referencia a los mismos se encuentra en la carta de Esquivel de 20 de febrero, donde indicó a 
Cepero en una postdata que "Gutiérrez tiene medio hechos los seis apóstoles"24. Ninguno de estos se encontraba en su colección a su muerte, y esa indicación tampoco permite concluir que llegara a realizarlos, pues pudo ser simplemente una afirmación que Gutiérrez hiciera a Esquivel para que este tranquilizara al comitente. Además, no ha de olvidarse que Esquivel hizo un séptimo apóstol, quizás después de esta carta, lo que demostraría, al menos, que Gutiérrez de la Vega no había cumplido por completo su encargo.

Finalmente, los otros lienzos conocidos fueron realizados por Ángel Saavedra (1791-1865), III duque de Rivas, de cuya participación, empero, no hay ningún rastro documental en el archivo particular del deán. Antonio Rumeu ya indicó que el duque había realizado para el coro cuatro cuadros: entre 1837 y 1838, Santa Rufina (Figura 6) y Santa Justa (Sevilla, catedral) y, en 1842, San Hermenegildo y San Fernando, que se encontraban en la colecturía de la catedral en $1935^{25}$, pero que en la actualidad están sin localizar $^{26}$. A pesar de que su estado de conservación dificulta el estudio de estas obras en profundidad, su resultado es, sin duda, mucho más discreto que las de Cabral Bejarano y Esquivel. Cepero y Saavedra tuvieron cierta amistad, pues este le dedicó y regaló algunos de sus libros $^{27}$, y es posible que por ello solicitase su colaboración con estas cuatro pinturas que, al no realizarse el proyecto, su autor decidió donar a la catedral ${ }^{28}$.

Desconocemos los motivos por los que los cuadros no llegaron a ser colocados en la sillería. Desde principios de 1837, Cepero, como mayordomo de fábrica de la catedral, había tenido que solventar la falta de recursos para "continuar con las obras de la torre y otras que el cabildo tenía determinadas y manifestó ser preciso atender a la reparación del monumento, a la composición y renovación de los ornamentos sagrados y a otras varias cosas indispensables para la decencia del culto divino"29. Y por ello, el cabildo decretó en agosto de ese año la supresión de numerosos puestos y cargos de cantores, capellanes y sacristanes, así como de otros gastos. Esta reducción dificultó la ejecución de algunos proyectos que él había impulsado, como el traslado de algunos sepulcros de sevillanos ilustres, pero no afectó a este del coro, que aún seguía en pie a principios del año

${ }^{24}$ A.D.L.-C., leg. 8/1, carta de Antonio María Esquivel a Manuel López Cepero.

${ }_{25}$ RUMEU, Antonio: "El duque de Rivas, pintor", Revista española de Arte, 8, 12 , 1935, pp. 345-352 y pp. 348-349.

${ }^{26}$ Según la información proporcionada por el Servicio de Información de Bienes Culturales del Instituto Andaluz del Patrimonio Histórico (consultado el 22-6-2016).

${ }^{27}$ Algunos de ellos, procedentes de la biblioteca de Cepero, permanecen aún entre sus descendientes.

${ }^{28}$ VALDIVIESO, Enrique: Catálogo de las pinturas de la catedral de Sevilla. Sevilla, 1978, p. $140, n^{\circ}$ cat. 538 y 539.

${ }_{29}$ Así se recoge en la sesión capitular de 18 de enero de 1837. A.C.S., Secretaría, serie Actas Capitulares, lib. 200, sig. 7248, f. 11v. 
siguiente, como confirman las cartas de Esquivel, y el hecho de que el duque de Rivas firmase en 1838 su Santa Justa. No cabe duda que esta carestía motivó que Cepero, al igual que en la traslación de los enterramientos de algunos personajes -donde buscó la colaboración de los descendientes de estos-, pretendiera que los artistas pudieran ayudar de manera desinteresada, y posiblemente fue esto lo que terminó acabando con su ambicioso plan, al que tampoco parece que la catedral llegara a destinar fondos ${ }^{30}$. De hecho, Amador de los Ríos, al referirse a los apóstoles y a los arcángeles que había en su colección, señalaba que "ecsisten [sic] en poder del señor Cepero, por no haber podido satisfacer el cabildo su importe" ${ }^{\prime 1}$. Frustrado, por tanto, el plan, su impulsor decidió guardar todos los cuadros concluidos, así como los bocetos de Cabral Bejarano. Si bien en su casa no presentaron ninguna unidad, pues arcángeles y apóstoles se encontraban distribuidos por diferentes estancias, sí fueron enmarcados de manera uniforme, con el marco dorado al agua, liso, con ancho filo plano, entrecalle en caveto y canto en bocel que acostumbraba a emplear el deán en muchos de los cuadros de su colección. Amador de los Ríos destacó los dos conjuntos, tanto el de los "diez cuadros" de Bejarano como el de Esquivel, entre las obras contemporáneas de interés de aquella ${ }^{32}$.

\section{EL ENCARGO DE UNA ICONOTECA SINGULAR}

Cepero poseía a su muerte dos iconotecas perfectamente singularizadas, que se encontraban expuestas de manera agrupada, sin la dispersión que presentaban los ángeles y los apóstoles del conjunto anterior. De estas dos galerías de retratos, solo cuatro cuadros fueron puestos a la venta en 1860, mientras que el resto permanecieron en manos de la familia. La catalogación realizada por Regla Merchán en 1979 de todas las obras conservadas en poder de los descendientes del deán ${ }^{33}$, junto con el análisis del inventario post mortem y la localización de alguno de ellos permite el estudio y la diferenciación de ambos conjuntos.

El primero, más numeroso, estaba compuesto por 24 retratos, con medidas similares -en torno a 65 x $50 \mathrm{~cm}-$ y se trata de obras de los siglos XVII y XVIII. Veinte eran bustos de papas y los cuatro restantes representaban a personajes históricos españoles, como Gonzalo de Córdoba y Bernardo del Carpio (Madrid,

${ }^{30}$ En los libros, los únicos gastos que se recogen para el coro son los de 48 varas de esteras el 11 de octubre de 1836. A.C.S., Fábrica, serie Libros de Libranzas de Fábricas, lib. 255.

${ }^{31}$ AMADOR DE LOS RÍOS, J.: Sevilla pintoresca..., op. cit., p. 456.

32 Ibidem.

${ }^{33}$ MERCHÁN CANTISÁN, R.: Catálogo de la colección pictórica ..., op. cit. Los retratos no fueron identificados en este catálogo como pertenecientes a un mismo conjunto: $\mathrm{n}^{\circ} 232-237,321,336,341,342$ y $389-392$. 
colección particular $)^{34}$, y son estos los que fueron puestos a la venta en 1860 . Todos ellos debieron ser adquiridos por Cepero después de 1823, ya que no aparecen en inventarios anteriores.

Mayor relevancia presenta la segunda galería de retratos, compuesta por veinte cuadros, y que fue encargada y formada en su totalidad por el deán. Estas obras, de menor tamaño que en la anterior -en torno a $45 \times 25 \mathrm{~cm}-$, presentaban un formato vertical, como confirman también alguno de los cuadros identificados. En las descripciones del inventario post mortem se consignan como sus autores "Escribano" - en siete de ellos-y "Rodríguez" - con trece obras-. Respecto al primero no hay duda de que se trata de Francisco de Paula Escribano (1820-1900). El segundo puede referirse a Juan Rodríguez Jiménez, el Panadero (1765-1830) o a su hijo Juan Rodríguez García, también apodado el Panadero (1816-h. 1880), nacidos ambos en Jerez de la Frontera, de donde era oriundo el propio Cepero, si bien de ninguno de ellos se han localizado más referencias en su archivo personal. Por algunas descripciones de Regla Merchán, sabemos que uno de estos retratos - del que ella no consigna autor- estaba fechado en 1839, lo que permitiría datar la realización de esta iconoteca hacia esa fecha, y suponer por tanto que fueran pintados por Juan Rodríguez García. La localización de los retratos de Alonso Cano (Sevilla, colección particular) y de Pablo de Céspedes (Figura 7), ninguno de los cuales está firmado ni fechado, permite confirmar la autoría de este en, al menos, estas dos efigies e imaginar cuál debía ser el sentido de esta iconoteca. Ambos aparecen de pie, el primero modelando un busto con las manos y el segundo apoyado en un bufete; remiten, en los dos casos, a la serie de personajes ilustres grabada en la Imprenta Real en 1791, sobre todo el retrato de Céspedes, muy cercano a la estampa de Tomás López Enguídanos. Es posible, por tanto, que el resto de obras presentasen un formato similar, ya que, por las medidas, todos debían estar representados de cuerpo entero, un tipo de retrato característico de las galerías familiares nobiliarias, pero inusual en las iconotecas, compuestas normalmente por retratos de busto o de medio cuerpo.

La selección de personajes de esta galería muestra los gustos artísticos del deán y sus intereses intelectuales. Así, eligió sobre todo a pintores y escultores -Velázquez, Murillo y el mencionado Cano- y a escritores del Siglo de Oro -Lope de Vega, Cervantes, Garcilaso y Quevedo-, los mismos que tenían protagonismo, respectivamente, en su galería y en su biblioteca. Rodríguez García además fue el autor de las efigies de Juan Sebastián Elcano, Cristóbal Colón y Fernando Magallanes y del cardenal Gil de Albornoz, Pablo de Céspedes y el Gran Capitán. Por su parte, Escribano realizó los retratos de los Reyes Católicos, Carlos V y Felipe II, Vasco Núñez de Balboa y Alberto Lista y Félix José Reinoso. Estos dos últimos son los únicos personajes contemporáneos que aparecen en la iconoteca y su inclusión

${ }^{34}$ En el inventario post mortem (A.D.L.-C., leg. 5/660), los números 1035 al 1050 recogen 16 papas y los números 242-249, el resto y los cuatro personajes históricos. 
en ella se debe, independientemente de su relevancia como escritores, a su estrecha amistad con Cepero.

Es cierto que esta galería de retratos resulta más bien modesta, pues no supera las 44 efigies entre los dos conjuntos; por tanto es muy inferior a las de Valentín Carderera (1796-1880) y Romualdo Nogués (1824-1899) -quizá las dos iconotecas privadas más importantes de la centuria antepasada-, y también a la que los duques de Montpensier instalarían poco después en su palacio de San Telmo (Sevilla). Pero, al igual que esta, fue realizada en buena medida por artistas contemporáneos y no con pintura antigua, como las de Carderera y Nogués. Sin embargo, las veinte obras de Escribano y el Panadero no eran meras copias de efigies históricas y presentaban un aspecto unitario, pues tenían el mismo tamaño y formato, lejos de la desigualdad que había en el conjunto de San Telmo. Además, la creación de esta iconoteca es posterior a la de Cepero. Por ello, si aceptamos que este encargó la suya hacia 1839, estaríamos ante la primera de carácter privado de las formadas en España en la centuria decimonónica. Más destacable aún es su homogeneidad, pues otras galerías de retratos como el Museo Iconográfico -creado en 1876-, o algunas privadas, como las ya mencionadas, carecieron de unidad, bien porque se formaron por acumulación de retratos de diferentes épocas o bien porque prevalecía la fidelidad al retrato original.

\section{LAS COPIAS DE OBRAS DE MURILLO Y ZURBARÁN}

Como todas las colecciones, la del deán también contaba con numerosas copias, que llegaban a la decena -nueve de originales de Murillo y una de Zurbarán-, una cantidad relativamente pequeña si se tiene en cuenta que el total de obras superaba el millar. Sin embargo, todas ellas respondían, de nuevo, a unas características muy similares y debieron ser encargos del propio Cepero a Salvador Gutiérrez, José Gutiérrez, Francisco de Paula Escribano, Antonio Cabral Bejarano y Rodríguez el Panadero hijo ${ }^{35}$. Al primero correspondían dos de las de menor tamaño $(44 \times 51 \mathrm{~cm}$ ), las únicas cuya historia material ha podido ser trazada, aunque en la actualidad se ignora su paradero ${ }^{36}$. Se trata de las copias de $E l$ regreso del hijo pródigo y de La curación del paralítico en la piscina probática, cuyos originales -que se encuentran en la National Gallery of Art de Washington y en la National Gallery de Londres- eran dos obras de Murillo salidas de Sevilla durante la Guerra de la Independencia ${ }^{37}$. De similares dimensiones a las dos

${ }^{35}$ En el inventario post mortem (A.D.L.-C., leg. 5/660) las copias presentan los siguientes números: 301, 344, 464, 667, 668, 865, 940-942 y 988.

${ }^{36}$ MERCHÁN CANTISÁN, R.: Catálogo de la colección pictórica..., op. cit., catá$\log \mathrm{n}^{\mathrm{o}} 363$ y 364 .

37 También de este autor debía ser la copia de San Félix de Cantalicio que cita Amador de los Ríos, pintada según él para el "Sr. Tafalla” y que no se encontraba en manos del 
primeras era la copia de Bejarano de un fragmento de La muerte de santa Clara, cuyo original se encuentra en la Gemäldegalerie Alte Meister de Dresde, y que también había salido de la ciudad en esa época. Es posible, por tanto, que, dadas las similitudes de tamaño entre ellas y la suerte similar que habían tenido los originales, estas tres copias fueran fruto de un único encargo, destinado a perdurar en la memoria del deán tres de las pinturas más relevantes salidas de la ciudad.

Las demás copias han de ser posteriores, y cabe vincularlas con la formación del Museo de Sevilla, en la cual el deán jugó un papel fundamental, como ya se ha estudiado ${ }^{38}$. Excepto el San Leandro de José Gutiérrez, copia del de la catedral -y el de mayores dimensiones-, las otras seis lo eran de cuadros procedentes de conventos sevillanos, en su mayoría del de Capuchinos, como el Santo Tomás de Villanueva y el San Antonio de Padua (Sevilla, Museo de Bellas Artes), cuyo traslado, junto con los otros veinte murillos, había sido responsabilidad de Cepero, que recordaba aquella proeza con especial orgullo ${ }^{39}$. Estas seis copias presentaban un tamaño similar, salvo la de la Virgen de la Servilleta, que, dadas las reducidas dimensiones del original, se reprodujo a menor escala. De nuevo, las semejanzas de las medidas y las similitudes entre la historia de los originales evidencia que el deán las pensó como un conjunto unitario, que le permitiría recordar algunas de las obras trasladadas al Museo recién fundado más importantes, como las tres últimas citadas, y las copias de la Apoteosis de Santo Tomás de Aquino de Zurbarán, y de la Inmaculada Concepción colosal (La Colosal) y la Adoración de los pastores de Murillo, que completaban esta serie. Para la realización de estas acudió a Escribano y a Rodríguez García, quienes también realizaron su iconoteca. Todas estas copias revelan una auténtica admiración por Murillo, que era el protagonista más destacado de su colección de pintura antigua.

\section{SU RELACIÓN CON ESQUIVEL, ANTONIO CABRAL BEJARANO Y OTROS PINTORES. SUS RETRATOS.}

Por lo que evidencian las fuentes consultadas, Cepero mantuvo una relación mucho más estrecha con Antonio María Esquivel que con el resto de artistas. A pesar de ello, esta resultaba casi totalmente desconocida, ya que hasta ahora solo se había indicado la presencia en la colección del primero de los mencionados apóstoles y del retrato que le hiciera años después y que aún hoy conservan los

deán a su muerte. AMADOR DE LOS RÍOS, J.: Noticia de los principales monumentos artísticos..., op. cit., p. 57. Véase también CÓMEZ RAMOS, Rafael: "Coleccionistas de pintura en Sevilla en 1842", Laboratorio de Arte, 5, 1993, pp. 160-161, donde se indica que el autor de esta obra fue José Gutiérrez de la Vega.

${ }^{38}$ MOYA VALGAÑÓN, José Gabriel: "Sobre los inicios del Museo de Bellas Artes de Sevilla", Berceo, 161, 2011, pp. 11-29.

39 PABÓN, J.: "Del Deán López Cepero...”, op. cit., pp. 471 y 472. 
descendientes (Sevilla, colección particular) ${ }^{40}$. Sin embargo, Cepero debió jugar un papel clave en la etapa madrileña del pintor sevillano, tal y como demuestran diferentes cartas. En una de ellas, sin fechar, escrita desde Madrid por su amigo Félix José Reinoso, este le indicaba que "hoy he estado dos veces a casa de Mier, y no lo he encontrado. Luego que con él hable, tentaré los caminos que él me franquee o yo encuentre para Esquivel, a quien no conozco"41. La carta muestra el tutelaje que el deán ejercía sobre el pintor, pues se preocupaba de ayudarle con sus contactos, uno de los cuales debía ser Enrique Mier Gutiérrez, cuyas relaciones, debidas a su trabajo como correo de gabinete del exterior ${ }^{42}$, podían serle útiles. Tanto Mier como Reinoso sirvieron de conexión entre Cepero y Esquivel en alguna otra ocasión. Así, Reinoso indicaba a Cepero que "estoy a la vista del negocio de Esquivel, de que hasta ahora no he tenido contestación"43. Quizá para agradecer al deán su apoyo y generosidad, el pintor le obsequió con un pequeño cuadro de San Miguel arcángel expulsando a Luzbel del Paraíso (Figura 8) ${ }^{44}$. Esta obra, mencionada ya por Amador de los Ríos ${ }^{45}$, pero que había permanecido inédita hasta ahora, presenta en su parte inferior una dedicatoria que resulta reveladora de la estrecha relación que mantuvieron Cepero y Esquivel: "Antonio M. Esquivel a su amigo M. L. Cepero/ Sevilla año de 1839”. El pequeño lienzo debe corresponder más bien con uno de los dos cuadros realizados en ese año como bocetos del Ángel Bueno y el Ángel Malo. Así lo señaló ya Guerrero Lovillo, quien estimó que la obra del deán había sido el punto de partida para la realización poco después del gran cuadro de La caída de Luzbel (Museo del Prado, 1840) que el pintor regaló al Liceo de Madrid en agradecimiento a la ayuda que le prestaron sus miembros durante su ceguera.

Para curarse de esta enfermedad, Esquivel marchó a Alemania y a Francia. A su vuelta de este último país, donde visitaría la Galería Española de Luis Felipe de Orleans en el Museo del Louvre, parece que el artista decidió denunciar a Cepero, pues no en vano este fue uno de los que había vendido obras al barón Isidore Justin Séverin Taylor con destino a este museo. Así se deduce de una carta

${ }^{40}$ Véase respectivamente GUERRERO LOVILLO, J.: Antonio María Esquivel, op. cit., pp. 25-27; y MERCHÁN CANTISÁN, R.: El deán López-Cepero..., op. cit, lám. 1.

${ }_{41}$ A.D.L.-C., carta sin signatura y sin fecha, dentro del grupo de cartas de Félix José Reinoso.

42 Según consta en su expediente personal, Enrique Mier había sido nombrado correo de gabinete del interior en 1839. Archivo Histórico Nacional, $\mathbf{M}^{\circ}$ Exteriores, PP599, exp. 8045 .

${ }^{43}$ RUIZ LAGOS, M.: Epistolario del Deán López Cepero..., op. cit., p. 104, carta $\mathrm{n}^{\circ}$ 46, datada en Sevilla el 10 de junio, sin año.

${ }^{44}$ Debo agradecer a Pablo Melendo la noticia de este cuadro, así como su generosidad por haberme facilitado su publicación.

45 AMADOR DE LOS RÍOS, J.: Noticia de los principales monumentos artísticos..., op. cit., p. 57; y AMADOR DE LOS RÍOS, J.: Sevilla pintoresca..., op. cit., p. 456. 
que el erudito Antonio María de Cisneros y Lanuza envió al deán el 17 de septiembre de 1841, en la que le confesaba: "Acabo de saber casualmente que el pintor Antonio Esquivel, habiendo regresado de Francia hace muy pocos días, ha denunciado a V. al gobierno, como a sustractor de cuadros de los conventos suprimidos en esa, y que se manifiestan en París"46. A pesar de la dureza de las afirmaciones, resulta difícil comprobar que Esquivel llegase a realizar tal denuncia, de la que no se ha encontrado rastro documental alguno. Además, el artista y Cepero mantuvieron su amistad después de esta fecha. Así, en 1844 Cepero decidió encargar a Esquivel un nuevo retrato (Sevilla, colección particular) y aquel quedó satisfecho con el mismo, tal y como demuestra Esquivel en una carta que le dirigió al deán en respuesta a una misiva anterior: "Muy Sr. mío y amigo de mi mayor respeto; he recibido su apreciable, en que me dice haber quedado contento con el retrato, lo que ha sido para mí de mucha satisfacción, pues yo lo estoy poco de mis obras y me alegro infinito cuando personas como V. las encarecen" ${ }^{47}$.

La documentación personal del deán muestra que este poseyó en algún momento otras obras de Esquivel que, a diferencia de las anteriores, ya no conservaba a su muerte. Así, en dos de las muchas cuentas que se conservan del deán, aparecen "dos caprichos de Esquivel: muchachos haciendo travesuras con un perro", valuados, en una de ellas, en 1.000 reales $^{48}$. Aunque ninguno de estos documentos tiene fecha, el segundo, el que recoge las tasaciones, demuestra que se trataba de un envío a un tercero, probablemente fuera de Sevilla. De hecho, uno de estos dos cuadros parece ser el mismo que se puso a la venta en Madrid en $1860^{49} \mathrm{y}$, este mismo o su pareja, ha de ser el de la colección Bellver (Figura 9). Aunque carecemos de más documentos que lo demuestren, es posible que Cepero actuara de intermediario para colocar fuera de Sevilla más obras del artista en alguna otra ocasión, como hizo con otros pintores sevillanos. Es el caso de Antonio Cabral Bejarano, de José Domínguez Bécquer (1805-1841) y de Andrés Rossi (1781-1849), activos también en Sevilla, cuyos nombres aparecen en la primera cuenta donde se encuentran los "caprichos" de Esquivel. Del primero figura "el cigarrero y la cigarrera" y de los otros dos "cuatro majas y majo. 3 de Bécquer y uno de Rosi" ${ }^{50}$. Unas y otras correspondían al género costumbrista, habitual en la producción de todos ellos. Aunque Amador de los Ríos aludió en 1844 a que Cepero poseía "otros países y juguetes de este género" de Bejarano, y los valoró

46 A.D.L.-C., sin sig., carta de Cisneros y Lanuza al deán, Madrid, 17-9-1841.

47 A.D.L.-C., sin sig., carta 20-1-1845.

48 A.D.L.-C.., legs. 13/1 y 1/191. Hay una tercera cuenta donde aparecen "dos bocetos" de Esquivel, adquiridos en Sevilla en 1836. A.D.L.-C., leg. 1/198.

${ }^{49}$ El anuncio, publicado en el Diario oficial de avisos el 18 de noviembre de 1860, identificaba el asunto como "El juego de muchachos de Esquivel, en 1500, el capricho del pintor pintando los chicos en actitud de echar la lavativa al perro".

${ }^{50}$ A.D.L.-C., leg. 1/191. 
por encima de los arcángeles ${ }^{51}$, ninguna de estas era de su propiedad a su muerte. Este hecho, junto con el resto de referencias, indican que, al igual que hacía a menudo con la pintura antigua ${ }^{52}$, el deán también ejercía de intermediario para vender obra contemporánea.

Cepero conservó además hasta su muerte otros dos pequeños conjuntos realizados por artistas contemporáneos, en su mayoría andaluces. El primero estaba formado por cuatro pequeños cuadros -en tabla y lienzo- representando a los seises de la catedral hispalense, vestidos con el traje del Corpus - un cuadro- o de la Concepción -tres-. Dos de ellos fueron realizados por "Rodríguez" -quizá Juan Rodríguez García-, otro por Antonio Cabral Bejarano y uno más por Adrien Dauzats (1804-1868), pintor francés que participó en la misión española del barón Taylor y con el que Cepero mantuvo una fluida correspondencia. De todos, este último es el único que ha sido identificado, pues figura catalogado por Regla Merchán, quien indicó que estaba firmado y fechado en Sevilla en $1837^{53}$. Es posible que todos fueran realizados en ese año, en el que también se datan los grandes cuadros para el coro, y que, por ello, formasen parte de otro proyecto nunca materializado, y que estaría incompleto, como parece demostrar la desproporción entre los vestidos de Corpus y los de Concepción. Sí parece completo el conjunto de cuatro pequeños lienzos pintados por José Gutiérrez y que recogían escenas del Quijote, como "Don Quijote en la cueva de Montesinos" y "Sancho Panza en la Ínsula", cuyo rastro se pierde a partir del inventario post mortem ${ }^{54}$.

La relación de Cepero con los artistas contemporáneos queda reflejada también a través de los numerosos retratos que algunos de ellos le realizaron, gracias a los cuales es posible seguir la evolución de su personalidad y de su propia biografía. El más antiguo fue realizado por Richard Belgrave Hoppner (1786-1872), diplomático, hijo del conocido retratista inglés John Hoppner (1785-1810 ${ }^{55}$. La obra, hasta ahora inédita, se encuentra fechada en 1805 (colección particular ${ }^{56}$ ),

${ }^{51}$ AMADOR DE LOS RÍOS, J.: Sevilla pintoresca..., op. cit., p. 456.

${ }^{52}$ Sobre su papel como intermediario en la compraventa de obras de arte, véase especialmente MARTÍNEZ PLAZA, Pedro J., "Un encargo 'cuadresco'...”, op. cit.

${ }^{53}$ MERCHÁN CANTISÁN, R.: Catálogo de la colección pictórica..., op. cit., $\mathrm{n}^{\circ}$ cat. 32. La obra, que no ha sido localizada, no aparece recogida en PLESSIER, Ghislaine: Adrien Dauzats ou la tentation de l'Orient,catalogue raisonné de l'oeuvre peint. Burdeos, 1990.

${ }^{54}$ A.D.L.-C., leg. 5/660, inventario post mortem, 284-287. En la venta de 1868 figuran dos escenas de este asunto, realizadas por J. Jiménez, una de las cuales está fechada en 1865 , por lo que queda descartada toda posible identificación con los que poseía el deán, que además presentaban otros temas diferentes.

${ }_{55}$ Agradezco la ayuda ofrecida por John Wilson en la correcta identificación de la autoría del retrato.

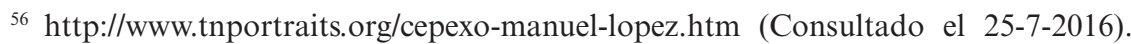
El cuadro presenta en el reverso una inscripción identificativa, del que se conserva una 
año en que Cepero fue nombrado examinador sinodal, y aparece en su inventario post mortem $\left(\mathrm{n}^{\circ} 527\right)$. De todas sus efigies, es sin duda la más interesante, al menos desde el punto de vista iconográfico. Le representa como un intelectual, entregado a la lectura. Su postura, con la cabeza apoyada en la mano derecha, recuerda a la del retrato de Jovellanos pintado por Goya. Hoppner, que había recibido de su padre su formación artística, estuvo destinado en Cádiz durante una misión diplomática en $1805^{57}$. Debió visitar también Sevilla y Jerez de la Frontera, pues estos nombres aparecen escritos respectivamente en el reverso del retrato de Cepero y en el de sus dos hermanas -Josefa y Rosario-, conocido únicamente por una fotografía antigua ${ }^{58}$. La existencia de estas dos efigies evidencia una estrecha relación entre Cepero y Hoppner, y supone una nueva evidencia de su contacto con el ámbito británico, que quizá debió empezar entonces. De hecho, Bartholomew Frere, a quien vendió numerosas obras durante la Guerra de la Independencia, era amigo del también pintor Lascelles Hoppner, hermano de Belgrave, por lo que es posible que este fuera el primero en establecer estas relaciones entre los británicos y Cepero.

José Gutiérrez de la Vega debió conocer a Cepero a través de su tío Salvador Gutiérrez, quien, como se ha visto, realizó algunas copias para este. La amistad entre ambos se remonta al menos a 1817, cuando se fecha el retrato que le realizó en su prisión de la Cartuja de Santa María de las Cuevas de Sevilla (Figura 1) ${ }^{59}$, donde había sido confinado en 1816 por orden de Fernando VII. El artista lo representa de busto prolongado, sin manos, con una mirada distante: su peinado y sus largas patillas ofrecen la imagen de un político liberal, que contrasta con su traje de eclesiástico.

El retrato de Esquivel de 1844 (Sevilla, colección particular), ya comentado más arriba, es sin duda el más conocido de todos ellos, y sirvió de modelo para la realización de otros posteriores, por el propio artista o por sus seguidores ${ }^{60}$. De todos ellos, este es sin duda el mejor ejemplo, por la cercanía y dignidad con la que aparece tratado el efigiado. Con toda seguridad, fue realizado para conmemorar su nombramiento como deán de la sede hispalense -por real decreto

fotografía en el Archivo Moreno: "Manuel López Cepero/ A la edad 27 años./ En Sevi1la/ por $\mathbf{M}^{\mathrm{x}}$ Hopner/ 1805". Instituto del Patrimonio Cultural de España (I.P.C.E.), Fototeca, $\mathrm{n}^{\circ}$ inv. 04858_C.

${ }^{57} \mathrm{http}: / /$ www.oxforddnb.com/index/76/101076824/ (Consultado el 25-7-2016).

${ }^{58}$ Esta fotografía del retrato, que también es únicamente de la trasera, presenta una inscripción similar al otro retrato. I.P.C.E., Fototeca, Archivo Moreno, 04858_C.

59 Este detalle lo sabemos gracias a las indicaciones del inventario post mortem: "474. 1. retrato del E. S. D. M. L. C. de m/c hecho en la cartuja de Sevilla por Gutiérrez".

${ }^{60}$ Destacan los retratos de Nazario Carriquiri (Madrid, Museo del Romanticismo), Antonio Domine (colección particular) y los dos de Miguel Donato (Madrid, Fundación FUSARA). 
de 12 de abril- y la concesión de la gran cruz de la orden de Isabel la Católica, que había recibido en enero de ese mismo año, y que ostenta orgulloso. El retrato es sin duda la mejor y más ajustada de todas las efigies que se conservan de este personaje y pertenece a un momento de especial importancia en su biografía. La obra retoma la imagen de hombre culto e ilustrado, que ya estaba presente en la pintura atribuida a Hoppner, pero con una nueva dimensión mucho más compleja. El personaje, que ha sido interrumpido durante su lectura, se hace acompañar de sus dignidades eclesiásticas y civiles (como el birrete y la condecoración recién recibida), y aparece con su galería de cuadros al fondo, que ha sustituido como fondo a la biblioteca de aquel otro retrato.

\section{CONCLUSIÓN}

Tanto el retrato de Hoppner como el de Esquivel reflejan la imagen de "humanista distinguido", calificativo con el que lo elogió José Velázquez y Sánchez ${ }^{61}$ y que permite entender las razones que se encuentran detrás de todos los proyectos donde el deán implicó a diferentes artistas contemporáneos, en especial sevillanos. El intento de reornamentación del coro, la creación de una iconoteca particular muy específica y el encargo de numerosas copias de pintura barroca de similares características resultan de especial relevancia para el coleccionismo y el mecenazgo privados de la primera mitad del siglo XIX, tanto en Sevilla como en el resto de España. Su proyecto para la catedral hispalense difícilmente puede equipararse con ejemplos contemporáneos de similares dimensiones y ambiciones, ya que otras intervenciones decorativas en edificios históricos, como el Palacio de San Telmo, fueron posteriores e implicaban una lectura muy diferente. Por otro lado, la galería de retratos históricos -encargados a jóvenes artistas andaluces- no posee parangón con ninguna otra durante toda la centuria, por mucho que las iconotecas alcanzasen unas dimensiones y consecuencias mucho mayores que las que tuvo en esta colección. También es difícil encontrar un conjunto de copias similar en otras galerías, dado que, al responder a una idea previa, presentan una gran homogeneidad y unidad.

La suma de todas estas obras, junto con otras más que poseyó, intercambió o vendió, muestran el peso que los pintores contemporáneos tuvieron en su colección; y que solo es comparable, en la primera mitad del siglo, al que tendrían en las de los duques de Montpensier o en la de la reina María Cristina de Borbón, donde, del mismo modo, las copias de maestros antiguos presentaban un destacado protagonismo. Salvo el coro, el resto de proyectos eran desconocidos hasta

${ }^{61}$ VELÁZQUEZ SÁNCHEZ, J.: Anales de Sevilla, reseña histórica de los sucesos politicos, hechos notables y particulares intereses de la tercera capital de la monarquía, metrópoli andaluza, de 1800 a 1850. Sevilla, 1872, p. 566. 
el momento. En conjunto revelan una nueva faceta del deán como comitente artístico de primer orden y permiten profundizar en el estudio de una de las personalidades culturales más importantes de toda la centuria en nuestro país, que hasta ahora había sido ponderado en especial como coleccionista de pintura antigua. La estrecha relación que mantuvo con Antonio María Esquivel difícilmente pudo sustentarse tan solo en el interés que Cepero pudo sentir por su obra, como se ha visto, y pudo estar motivada más bien por afinidades ideológicas y similares preocupaciones intelectuales, que pudieron granjearle al pintor la amistad y protección del deán, cuyo círculo más próximo estaba formado sobre todo por escritores como Reinoso o Nicasio Gallego, pero no por artistas. Finalmente, la identificación y localización de nuevos cuadros de algunos de los pintores sevillanos más destacados de su tiempo, permite avanzar en el conocimiento de la producción y de la biografía de todos ellos, para cuya promoción tuvo un destacado papel López Cepero.

Fecha de recepción: 18 de agosto de 2016

Fecha de aceptación: 4 de enero de 2017 


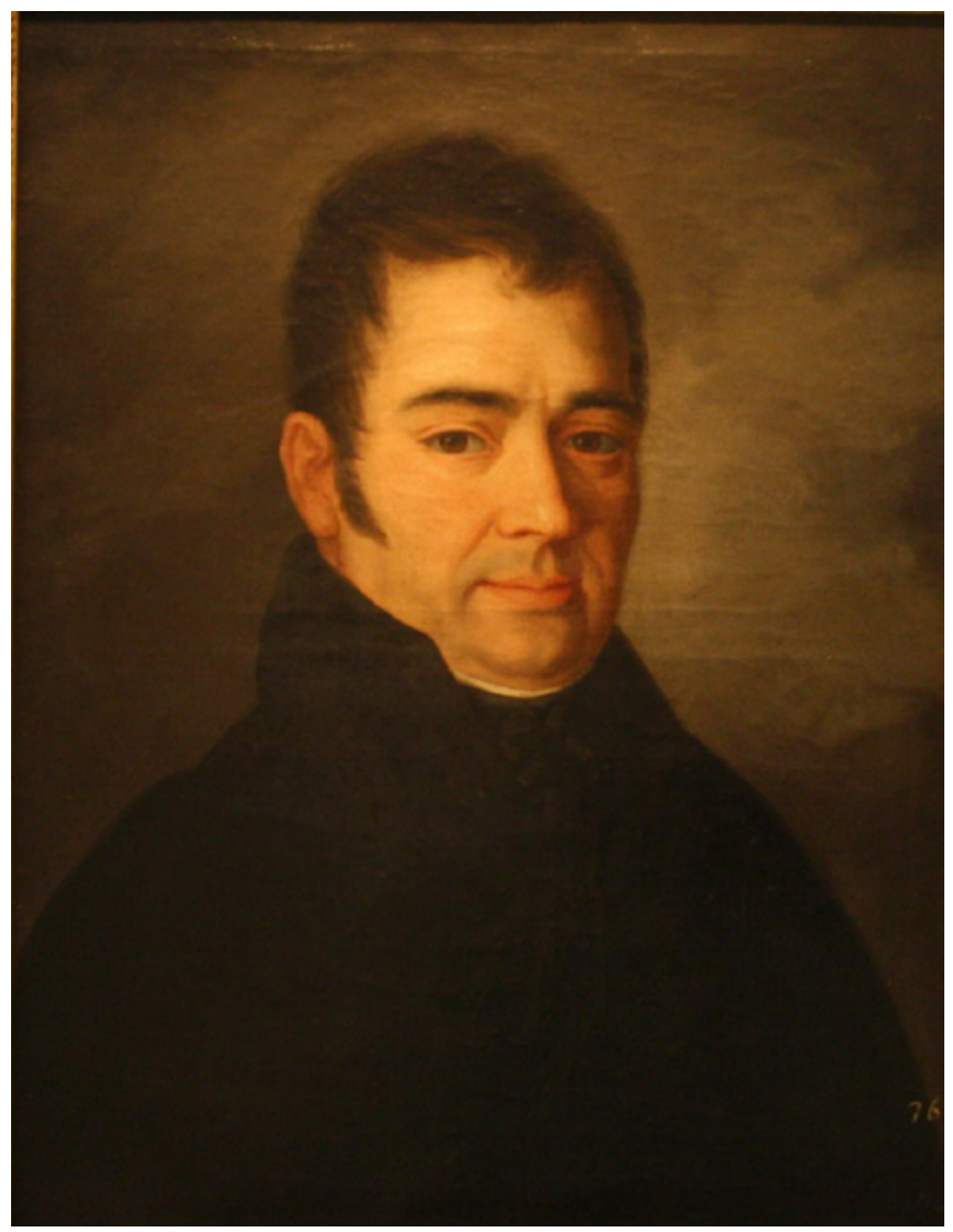

Figura 1. José Gutiérrez de la Vega, Manuel López Cepero, 1817, Museo de Pontevedra. 


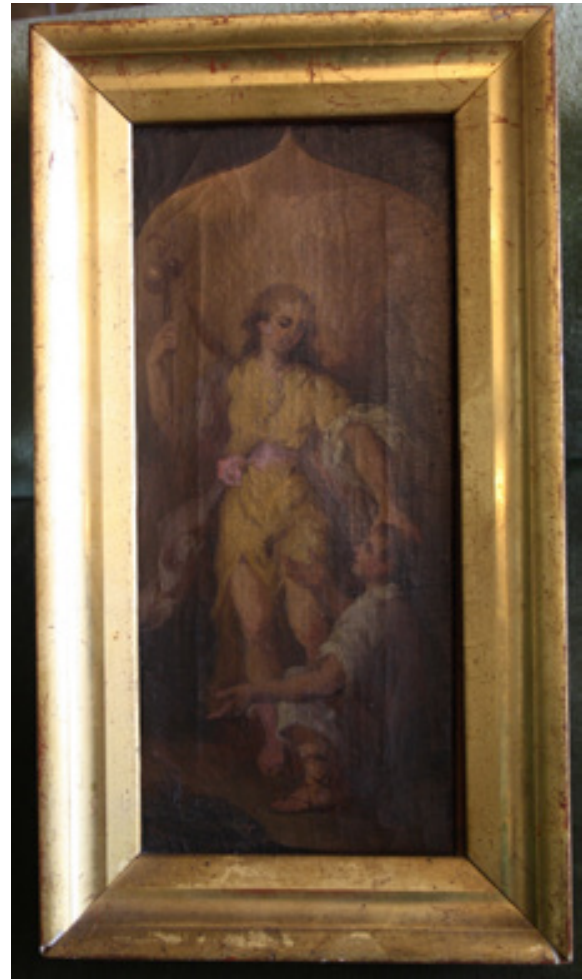

Figura 2. Antonio Cabral Bejarano, Arcángel Rafael (boceto), hacia 1837, colección particular.

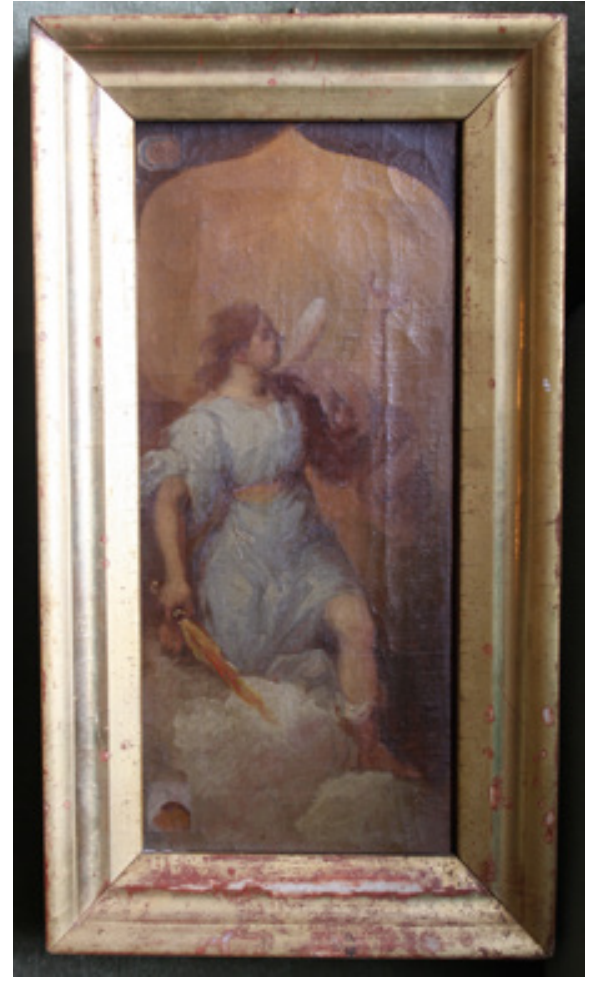

Figura 3. Antonio Cabral Bejarano, Arcángel Uriel (boceto), hacia 1837, colección particular. 


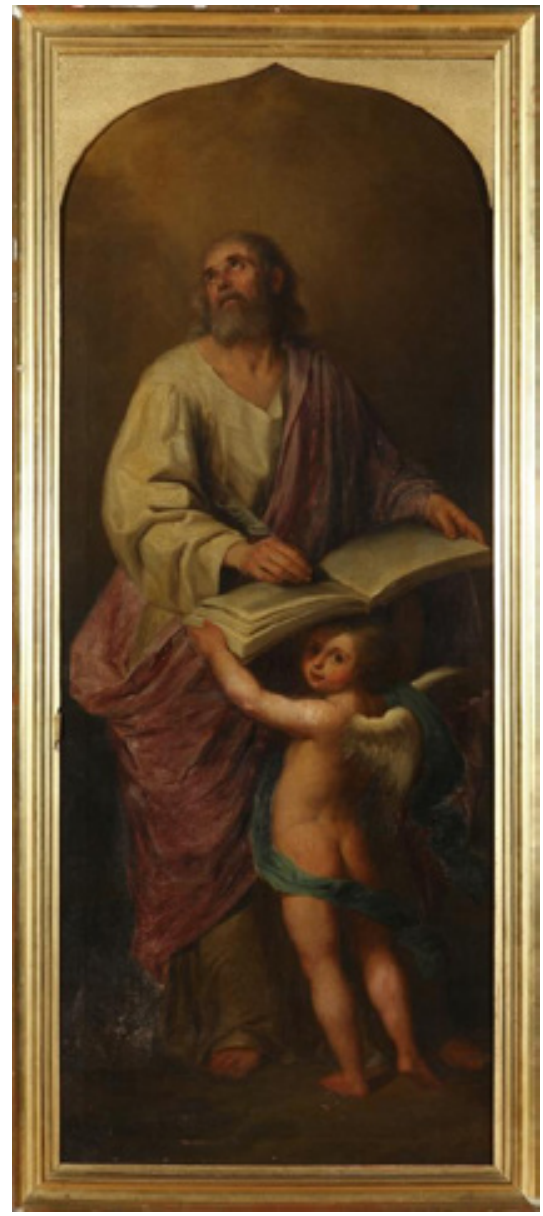

Figura 4. Antonio María Esquivel, San Mateo, 1837, Museo del Romanticismo, Madrid.

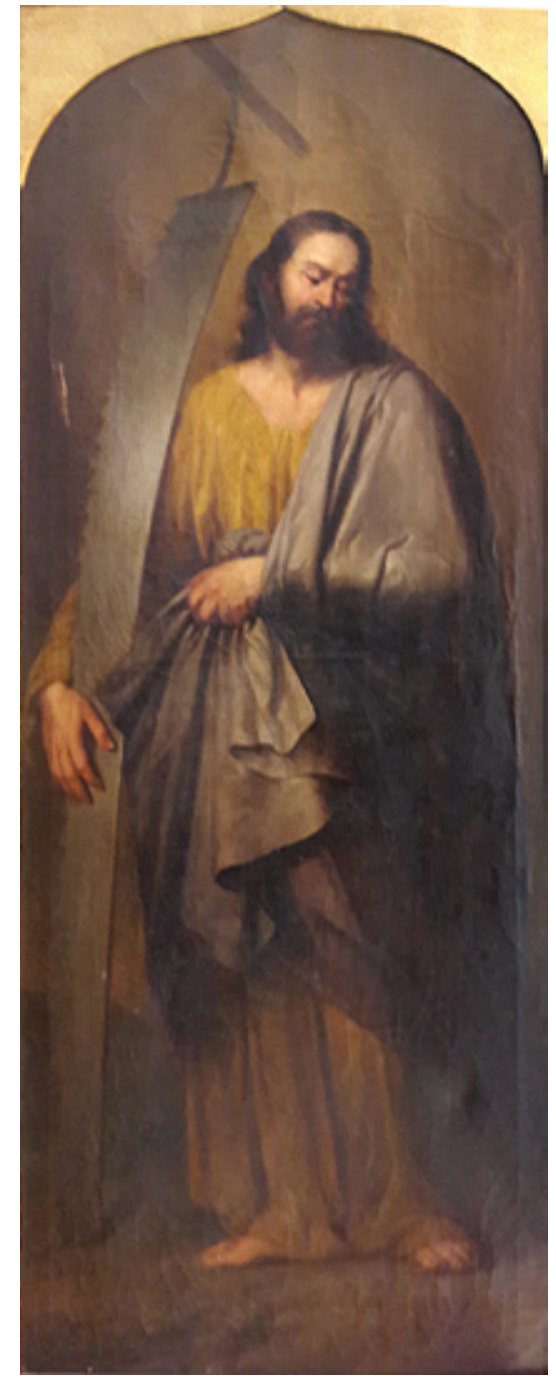

Figura 5. Antonio María Esquivel, San Simón, 1837, colección particular. 

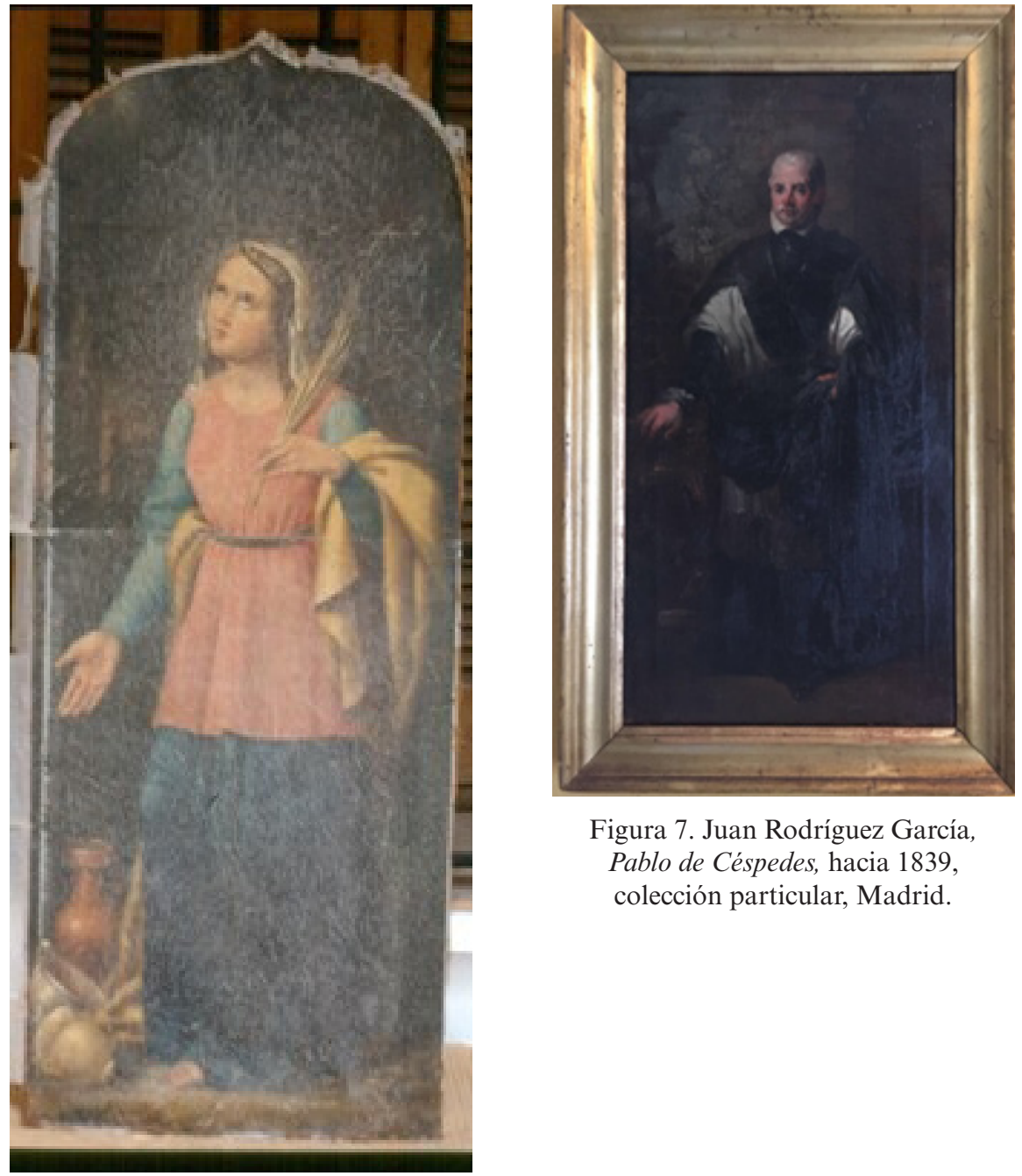

Figura 7. Juan Rodríguez García Pablo de Céspedes, hacia 1839, colección particular, Madrid.

Figura 6. Ángel Saavedra, Santa Rufina, 1838, catedral de Sevilla. 


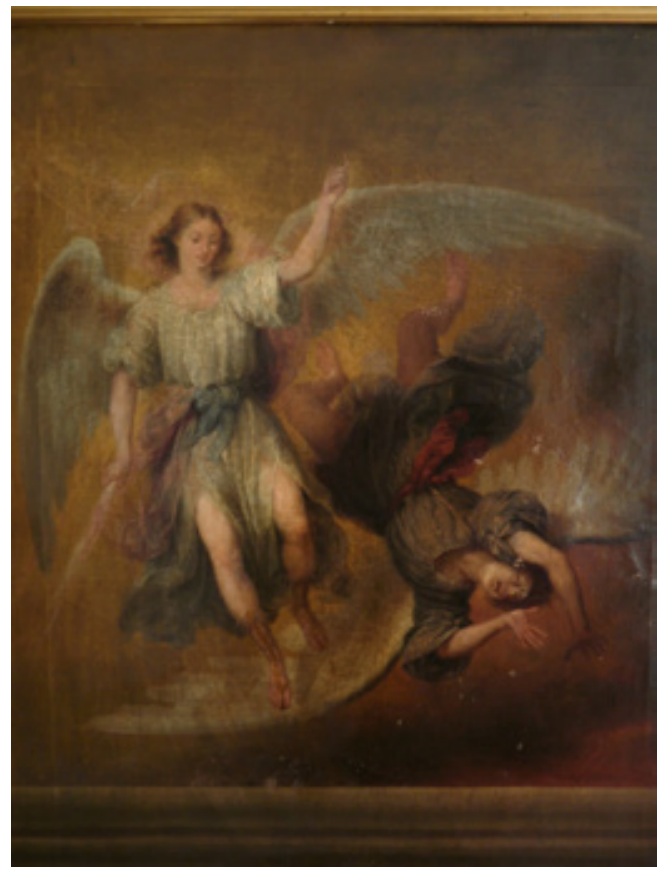

Figura 8. Antonio María

Esquivel, San Miguel arcángel expulsando a Luzbel del

Paraíso, 1839, colección particular.

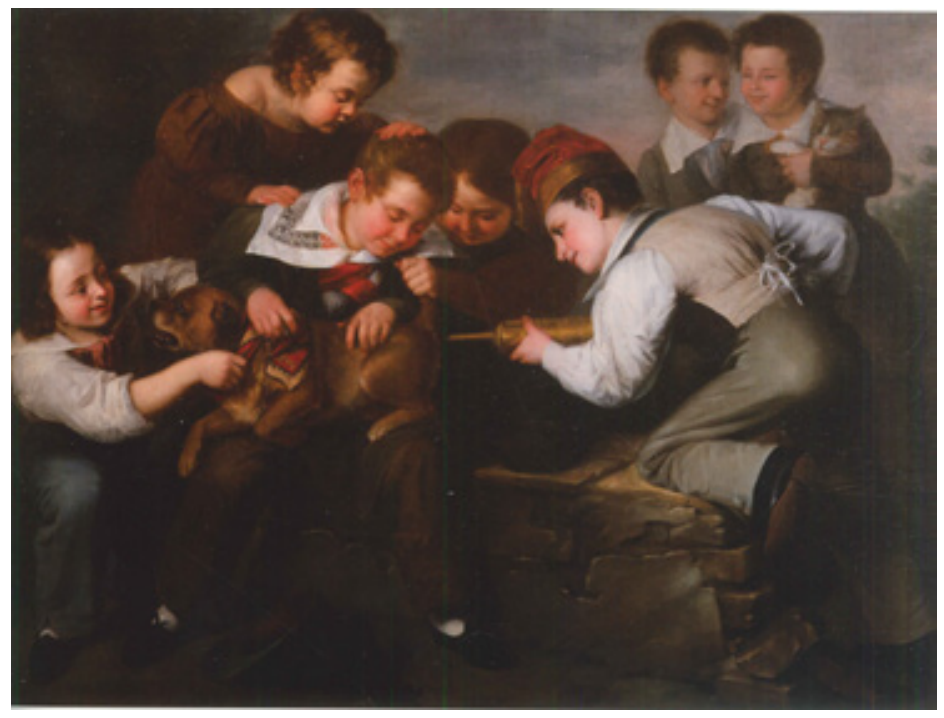

Figura 9. Antonio María Esquivel, Muchachos haciendo travesuras con un perro o Capricho, 1833, colección Bellver, Ayuntamiento de Sevilla. 